\title{
Stanislav Fakan \\ The functional architecture of the nucleus as analysed by ultrastructural cytochemistry
}

Accepted: 14 June 2004 / Published online: 5 August 2004

(C) Springer-Verlag 2004

\begin{abstract}
Ultrastructural cytochemistry has been, for many years now, a major tool for investigating structurefunction relationships in the cell nucleus. It has been essential in approaching the roles which different nuclear structural constituents can play in nuclear functions. This article briefly summarises transmission electron microscopic studies aimed at characterising in situ nuclear architectural domains and their involvement in main nuclear functions, such as DNA replication, hnRNA transcription and pre-mRNA processing. It discusses the importance of ultrastructural cytochemistry in high resolution analyses of intranuclear distribution of chromatin domains and their topological relationships with other structural interphase nuclear constituents. It puts forward the central role of the perichromatin region as a functional nuclear domain. Finally, it attempts to critically evaluate some future applications of ultrastructural investigations of the nucleus and stresses the importance of combining them with light microscopic analyses of living cells.
\end{abstract}

Keywords Ultrastructural cytochemistry $\cdot$ Nuclear architecture - DNA replication - Transcription · PremRNA processing

\section{Introduction}

The cell nucleus is defined by the nuclear envelope, consists of two main compartments, the nucleolus and the nucleoplasm, and its different internal structural constituents are not delimited by membranes (Fig. 1).

Robert Feulgen Lecture 2004 presented at the 46th Symposium of the Society for Histochemistry in Prague, Czech Republic, on 22 September 2004

S. Fakan (

Centre of Electron Microscopy,

University of Lausanne,

Rue du Bugnon 27, 1005 Lausanne, Switzerland

e-mail: stanislav.fakan@cme.unil.ch

Tel.: +41-21-6925052

Fax: +41-21-6925055
Methods of ultrastructural cytochemistry, extensively used during the last 40 years to analyse the morphofunctional relationships in the cell nucleus in situ, have provided a major contribution in investigating the nuclear functional architecture. Long before the first confocal microscope became commercially available, the applications of various methods of electron microscopic cytochemistry gave rise to a number of essential observations allowing one to characterise the nature of nuclear structural domains and to approach their possible roles in nuclear functions.

The most studied nuclear compartment is probably the nucleolus. It is the site of ribosomal RNA synthesis and processing and ribosomal subunit assembly. The nucleolus consists of three structural subdomains: fibrillar centres, dense fibrillar component and granular component. A large number of studies has been devoted to the morphofunctional aspects in the nucleolus, leading to sometimes controversial findings. Most observations support the dense fibrillar component as the major site of prerRNA synthesis (see, for example, Granboulan and Granboulan 1965; Cmarko et al. 2000; for more details see Fakan and Puvion 1980; Goessens 1984; Hozak 1995; Biggiogera et al. 2001; Raska 2003).

In this short review article, we will mainly concentrate on the contributions of ultrastructural cytochemical analyses to characterising different structural domains in the nucleoplasm and to unravelling their roles in essential functions of the cell nucleus such as DNA replication, transcription, RNA processing and storage.

Methods of transmission electron microscopic cytochemistry, although giving rise to two-dimensional images, offer a resolving power that is about two orders of magnitude superior to light microscopy, including confocal laser scanning microscopy (CLSM; Stelzer 1995). Their application has made major contributions in obtaining basic information about the nuclear functional architecture. Early ultrastructural studies (see, for example, Swift 1962; Smetana et al. 1963; Monneron and Bernhard 1969) already provided a fundamental pool of data necessary for further rapid advancement in this im- 


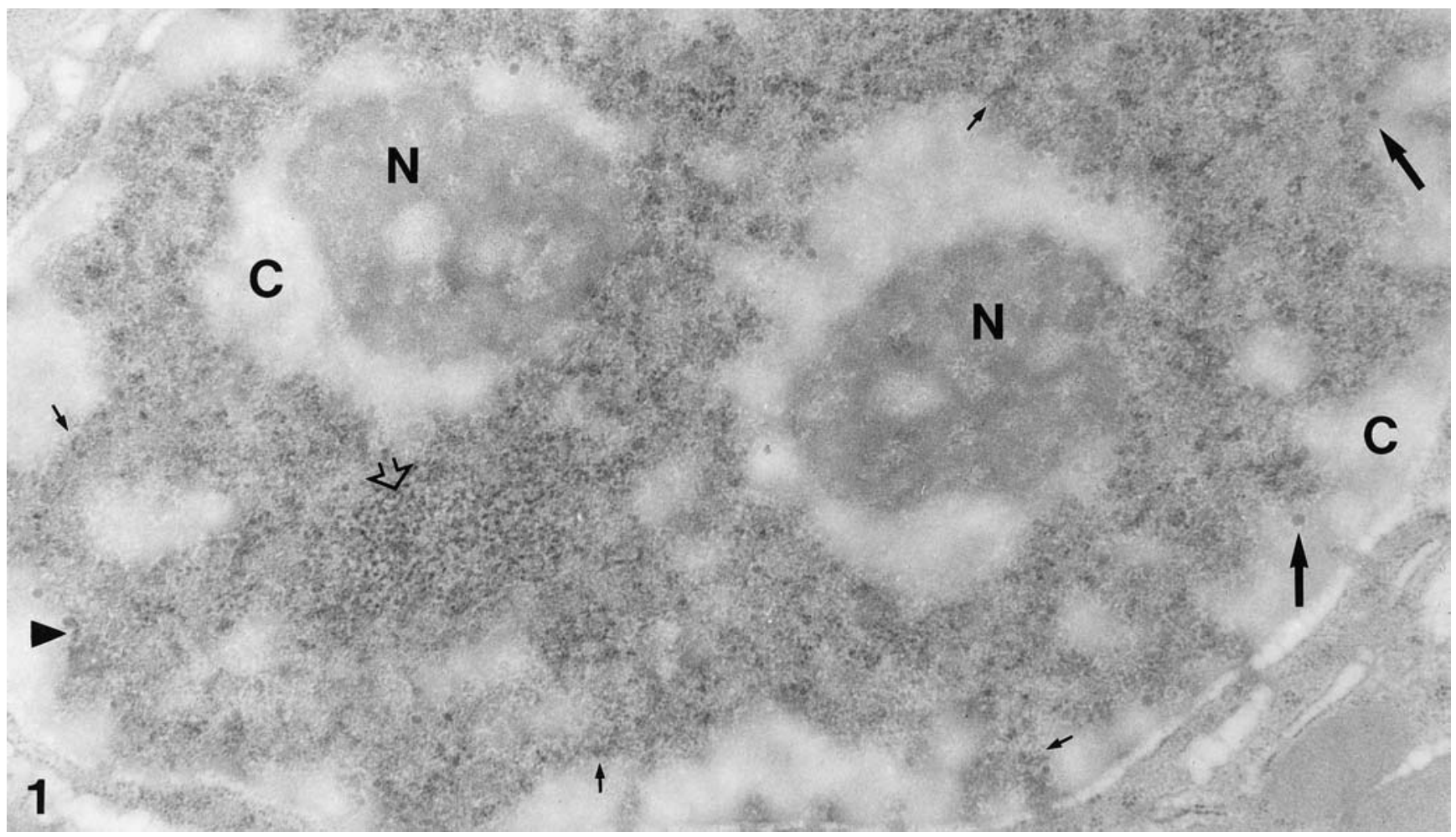

Fig. 1 Ultrathin section of a nucleus from a rat hepatocyte fixed in glutaraldehyde and embedded in Epon. EDTA staining preferential for nuclear RNP constituents (Bernhard 1969). Nucleoplasmic structures, such as perichromatin fibrils (some indicated by small arrows), perichromatin granules (some indicated by large arrows; arrowhead points to a perichromatin fibril giving rise to a perichromatin granule) and interchromatin granules (open arrow), as well as nucleoli $(N)$ are well contrasted, while chromatin $(C)$ appears light grey $(\times 30,000)$

trasting technique based on a Feulgen-type reaction with osmium ammine (Cogliati and Gautier 1973) allowing one to visualise DNA directly in ultrathin sections. This approach, extensively applied on different cell models (Biggiogera et al. 1996), can be combined with other methods such as immunocytochemistry and electron spectroscopic imaging (Biggiogera et al. 2001). Analysis of reconstructions from serial ultrathin sections of interphase nuclei revealed that about $50-60 \%$ of the nuclear space is filled by chromatin (Esquivel et al. 1989; LópezVelázquez et al. 1996), while the remaining volume is occupied by the interchromatin space with its structural interchromatin domains. The interchromatin space is largely devoid of DNA (Fig. 2).

The development of fluorescence in situ hybridisation (FISH) and of molecular probes for specific chromosomes made it possible to localise territories of individual chromosomes within the interphase nucleus (for more details, see van der Ploeg 2000; Cremer and Cremer 2001). Chromosome painting, as well as the possibility to localise a particular gene with regards to chromosomes in mitosis, has proved to be a powerful tool in genetic diagnosis and in biomedical research. Keeping in mind the relatively low resolution of any light microscopic observation, the application of these techniques in investigating the interphase nuclear architecture and the interpretation

of the results should be carried out with caution. In ad-
High resolution distribution of chromatin throughout the nucleus can be investigated by virtue of a specific con- 


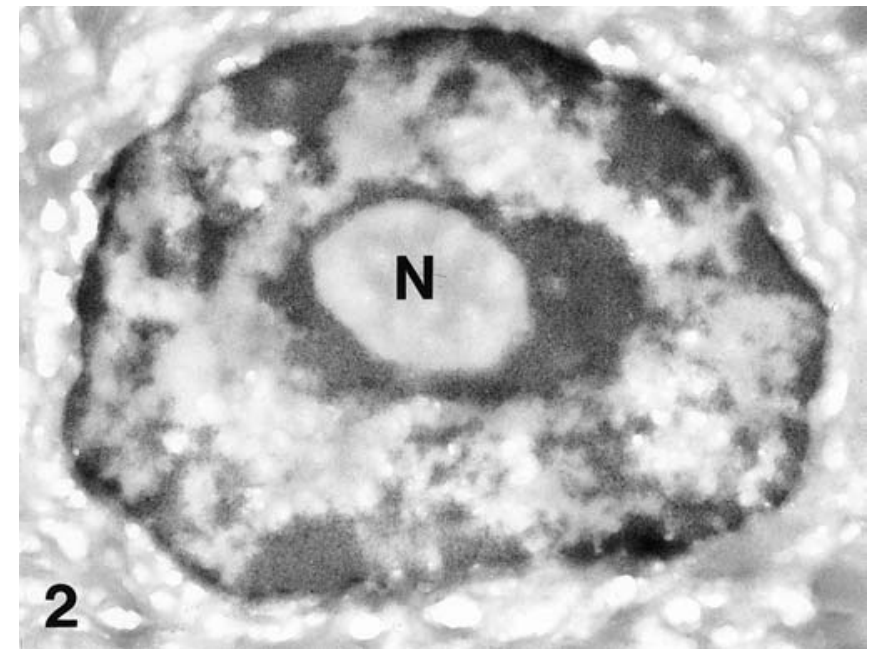

Fig. 2 Ultrathin frozen section of a mouse pancreas cell nucleus stained by the Feulgen-type reaction with osmium ammine (Cogliati and Gautier 1973) revealing specific distribution of DNA. $N$ Nucleolus $(\times 13,700)$

dition, FISH procedures aiming at visualising the distribution of DNA sequences in the specimen, make use of rather harsh treatments in order to keep the target and the probe DNA denatured. Usually applied after a relatively mild specimen fixation, it gives rise to extensive DNA dispersion within the nucleus, leakage of DNA into the cytoplasm and general degradation of the nuclear architecture as shown by subsequent electron microscopic analysis of FISH-submitted cell samples (Solovei et al. 2002). The denaturation steps lead to alveolation of nuclear fine structure and the original distribution of various nuclear domains is considerably altered. This shows that FISH techniques, as presently available, are hardly suitable for higher resolution studies, such as localisation of genes with respect to particular nuclear structural domains. Since ultrastructural methods allowing one to carry out chromosome painting or ISH investigation of specific genome sequences providing satisfactory signal without significant deterioration of the nuclear structure are not yet available, other approaches avoiding the use of too deleterious preparative conditions have been explored. In order to study the relationships of a given nuclear domain or territory with its neighbourhood in the nucleus, Visser et al. (2000) made use of the possibility to label DNA in living cells by means of halogenated deoxyuridines (dUs), which can be detected at the ultrastructural level, using selected anti-dU antibodies and immunocytochemistry (Jaunin et al. 1998). Cultured cells labelled during one S-phase with BrdU and subsequently allowed to grow for several cell cycles, exhibit in their nuclei one to a few labelled chromatin domains obviously representing chromosome territories. This approach further enabled the investigation of the structural relationships between such labelled domains and their unlabelled neighbours and revealed three typical patterns of contacts. In some cases, domains were separated by interchromatin space, showed chromatin fibre continuation with a sharp

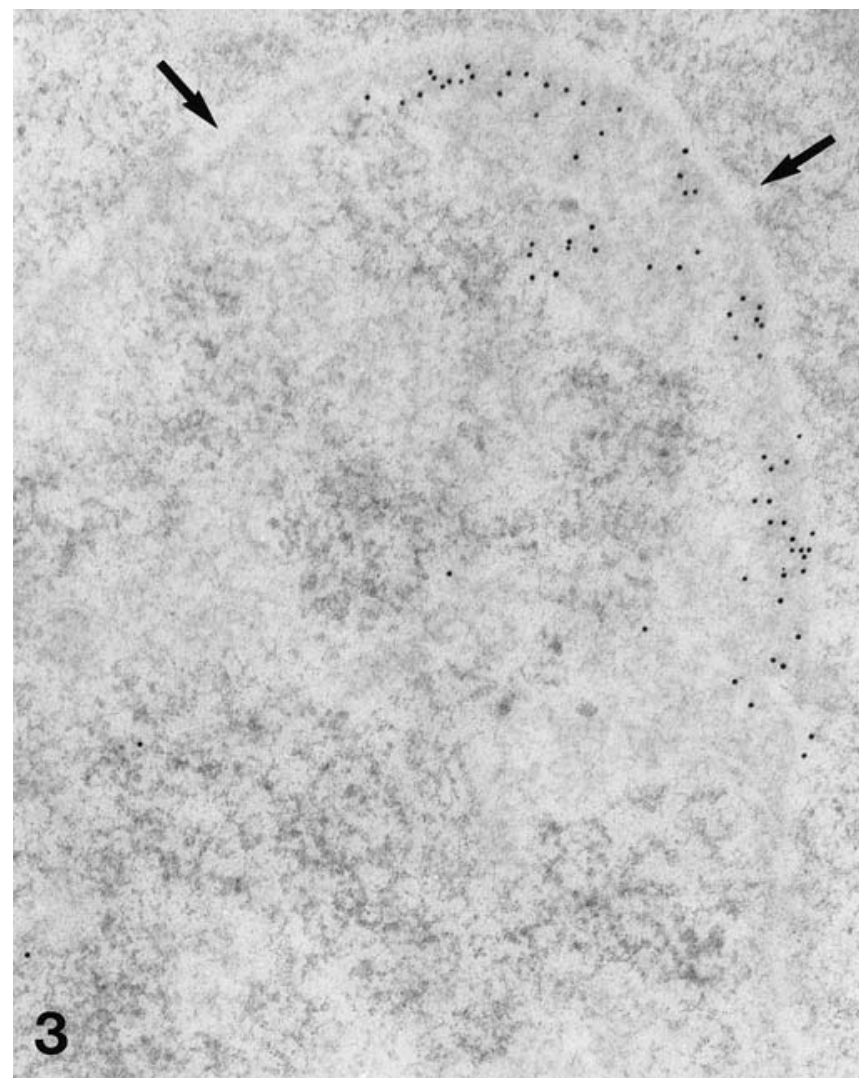

Fig. 3 Chinese hamster V79 cell labelled with BrdU for one Sphase and allowed to grow for a period of about five cell cycles. Ultrathin section stained with the EDTA method preferentially contrasting nuclear RNP constituents leaving chromatin light grey. Arrows indicate nuclear periphery. Gold grains label a chromatin domain probably belonging to the same interphase chromosome territory. For more details, see Visser et al. (2000). Micrograph by Françoise Jaunin. $(\times 55,000)$

limit of label, while sometimes the labelled DNA fibres were somewhat gradually interspersed with unlabelled fibres of the neighbouring domain, thus obviously favouring possible interphase interactions between chromosomes. Chromosome domains or territories are penetrated by numerous interconnecting channels as shown by reconstructions of small series of subsequent sections (Visser et al. 2000). Although this approach does not allow one to identify specific chromosomes, it proved to be a very useful alternative in analysing topological relationships between chromatin domains under conditions of excellent fine structural preservation (Fig. 3).

\section{Perichromatin region}

Thanks to the application of various ultrastructural cytochemical techniques in the investigation of functional nuclear architecture, it has become clear for more than 30 years now that the perichromatin region plays an important role in the expression of nuclear functions. Although rather difficult to be strictly defined, this nuclear structural domain is essentially determined by the border 
of condensed chromatin areas where a layer of more dispersed chromatin including somewhat free adjacent chromatin fibres occurs. The definition of the perichromatin region has been facilitated by the introduction of a differential contrasting method for ultrathin sections using chelating agents, which gives rise to a high contrast of ribonucleoprotein-containing nuclear constituents, while chromatin remains weakly stained (Bernhard 1969).

Earlier studies making use of radioactive precursors of RNA or DNA and high resolution autoradiography revealed that sites of hnRNA transcription (Fakan and Bernhard 1971) and of DNA replication (Fakan and Hancock 1974) are both mainly limited to the border of condensed chromatin areas on EDTA-stained specimens of cultured cells after short incubation periods with tritiated precursors (see Fakan 1978 for extensive review of autoradiographic data). Such experiments pointed out the involvement of the perichromatin region in essential functions of the nucleus later confirmed by non-radioactive labelling approaches offering a better localisation resolution. The introduction of halogenated nucleic acid precursors visualised by means of secondary colloidal gold-coupled markers and immunoelectron microscopy, opened new possibilities in the localisation of synthetic processes in the nucleus.

\section{DNA replication}

When localising DNA replication sites, halogenated deoxyuridine is easily administered to living cells. However, the incorporation period needs to be restricted as much as possible, taking into account the rapid replication rate (1$2 \mu \mathrm{m} / \mathrm{min}$; Huberman and Riggs 1968). In this way, several reports demonstrated predominant localisation of DNA synthesis in association with dispersed chromatin fibres occurring adjacent to or within the periphery of condensed chromatin areas (Sobczak-Thepot et al. 1993; Liu et al. 1995; Jaunin et al. 2000; Fig. 4). In addition, the perichromatin region also accumulated DNA polymerase $\alpha$, cyclin A and PCNA (Sobczak-Thepot et al. 1993; Jaunin et al. 2000). When the kinetics of newly synthesised DNA (nascent DNA) was examined in V79 Chinese hamster cells after staining of ultrathin sections with a Feulgen-type reaction by means of osmium ammine (Cogliati and Gautier 1973) specifically visualising DNA, Jaunin et al. (2000) observed that fractions of DNA replicated within the perichromatin region were rapidly internalised into condensed chromatin domains. Moreover, such movement of DNA synthesised during a limited period of time was also obvious in pulse chase experiments using iodinated or chlorinated dU incorporated in a sequence of two incubation periods separated by unlabelled chase and differentially revealed by anti-BrdU antibodies exhibiting high affinity for one of the precursors. Together, these experiments support the conclusion that, during the synthetic phase, DNA moves rapidly between the perichromatin region where it is replicated and the interior of chromatin domains where it is internalised

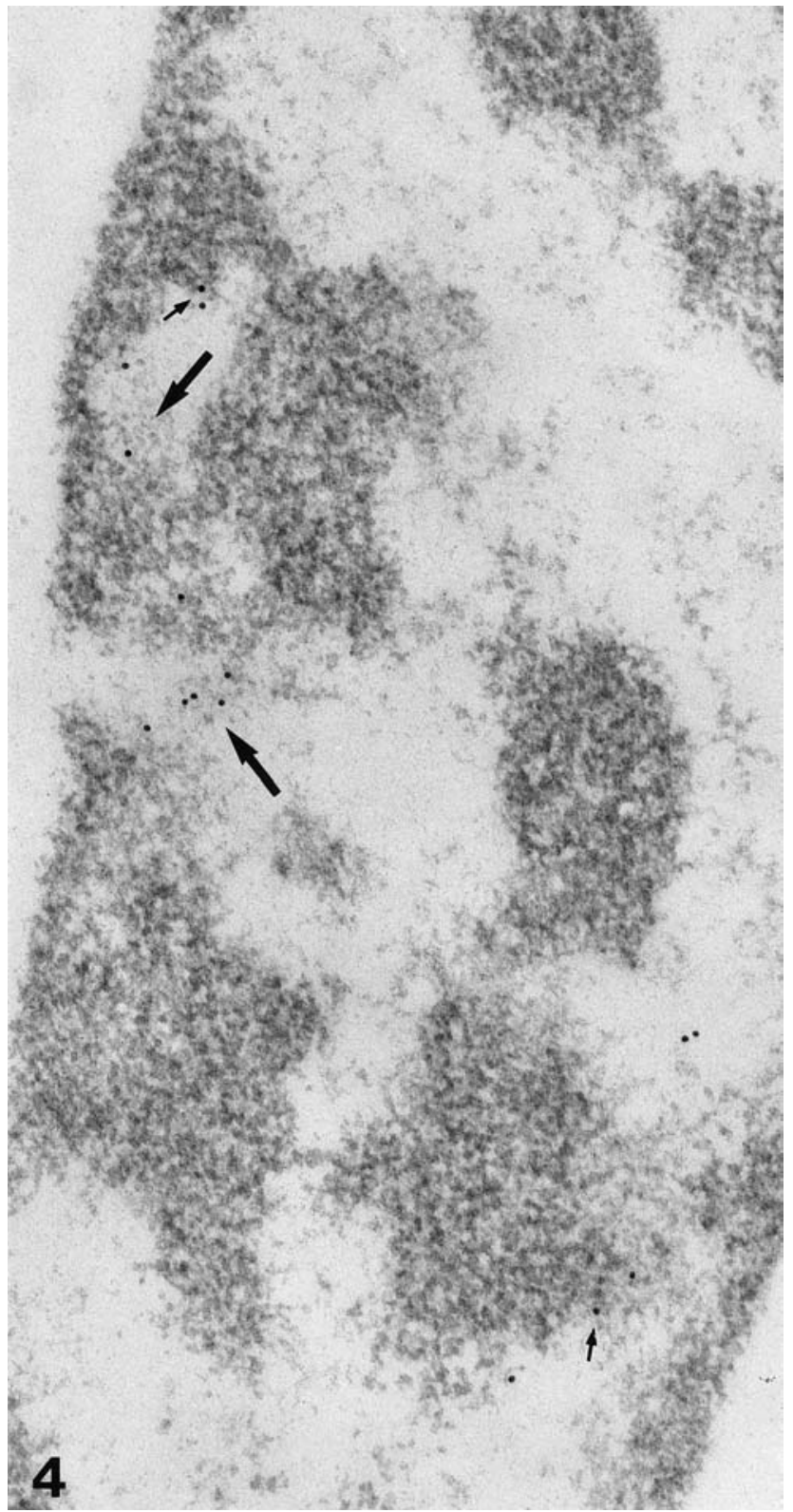

Fig. 4 Ultrathin section of a Chinese hamster V79 cell labelled with BrdU for $2 \mathrm{~min}$, fixed with paraformaldehyde and embedded into Lowicryl K4 M. Osmium ammine staining specific for DNA. DNA replication sites are visualised on the periphery of condensed chromatin (small arrows) sometimes associated with fibres of dispersed chromatin (large arrows). For more details, see Jaunin et al. (2000). Micrograph by Françoise Jaunin. $(\times 77,000)$

(Jaunin et al. 2000). As to the pattern of chromatin domains during the DNA synthetic period, chromatin appears rather dispersed in numerous spots during early $\mathrm{S}$ phase, while in late S-phase label occurs associated with larger condensed chromatin domains (O'Keefe et al. 1992; Leblond and el-Alfi 1996; Jaunin et al. 1998). However, the major replication pattern followed by internalisation of nascent DNA into the chromatin domains seems to be independent of S-phase period. A more detailed discussion about DNA replication topology studied 
by both light and electron microscopic visualisation approaches was presented earlier (Jaunin and Fakan 2002).

\section{Transcription sites}

Similar to DNA replication analyses, earlier studies demonstrated transcription sites localised on the border of condensed chromatin areas after short pulses of different cells in culture with ${ }^{3} \mathrm{H}$-uridine and revealing of rapidly labelled RNA by means of high resolution autoradiography (Fakan and Bernhard 1971; Fakan et al. 1976; for review see Fakan 1978; Fakan and Puvion 1980). Moreover, the application of the EDTA regressive staining (Bernhard 1969) allowed Monneron and Bernhard (1969) to describe a novel ribonucleoprotein-containing structural constituent abundant within the perichromatin region of nucleoplasm, the perichromatin fibril (PF). Later, autoradiographic investigations of hnRNA kinetics demonstrated the occurrence of rapidly labelled RNA in perichromatin fibrils (Nash et al. 1975; Fakan et al. 1976), thus confirming that they represent in situ forms of hnRNA transcripts (Fakan 1994). Furthermore, pulse chase experiments revealed that a significant fraction of labelled fibrils migrated, after their formation, into the interchromatin space (Fakan et al. 1976; Puvion and Moyne 1978).

The introduction of non-radioactive labelling methods of RNA by means of brominated precursors provided a new high resolution tool for investigating the in situ transcription features. Similar to halogenated DNA, incorporated brominated UTP can be visualised by means of anti-dU antibodies and immunocytochemistry. Original fluorescence microscopic studies of cells shortly labelled with Br-UTP (Jackson et al. 1993; Wansink et al. 1993) demonstrated the occurrence of signal either in a form of multiple small spots or as diffused fluorescence distributed throughout the nucleoplasm (Fig. 5). Immunoelectron microscopic analysis of ultrathin sections of cultured cells microinjected with Br-UTP (Cmarko et al. 1999) or incubated with Br-uridine (Trentani et al. 2003) revealed the perichromatin region as the main transcription site in the nucleoplasm containing perichromatin fibrils as rapidly labelled RNP constituents (Fig. 6). These observations, confirming earlier autoradiographic data, further showed that Br-labelled RNA resulting from short incubation periods is mostly represented by individual gold particles. Moreover, when combined with a specific staining of RNA using terbium citrate (Biggiogera and Fakan 1998), they ascertained direct association of signal with RNA fibrils (Trentani et al. 2003). Finally, immunocytochemical localisation to perichromatin fibrils of hnRNP core proteins by means of specific monoclonal (Leser et al. 1984) or polyclonal (Jones et al. 1980) antibodies (Fakan et al. 1984; Malatesta et al. 1994a; Cmarko et al. 1999) brought additional evidence about the hnRNP (or pre-mRNP) nature of this nuclear structural constituent. Perichromatin fibrils visualised in the perichromatin region are also major sites of associa-

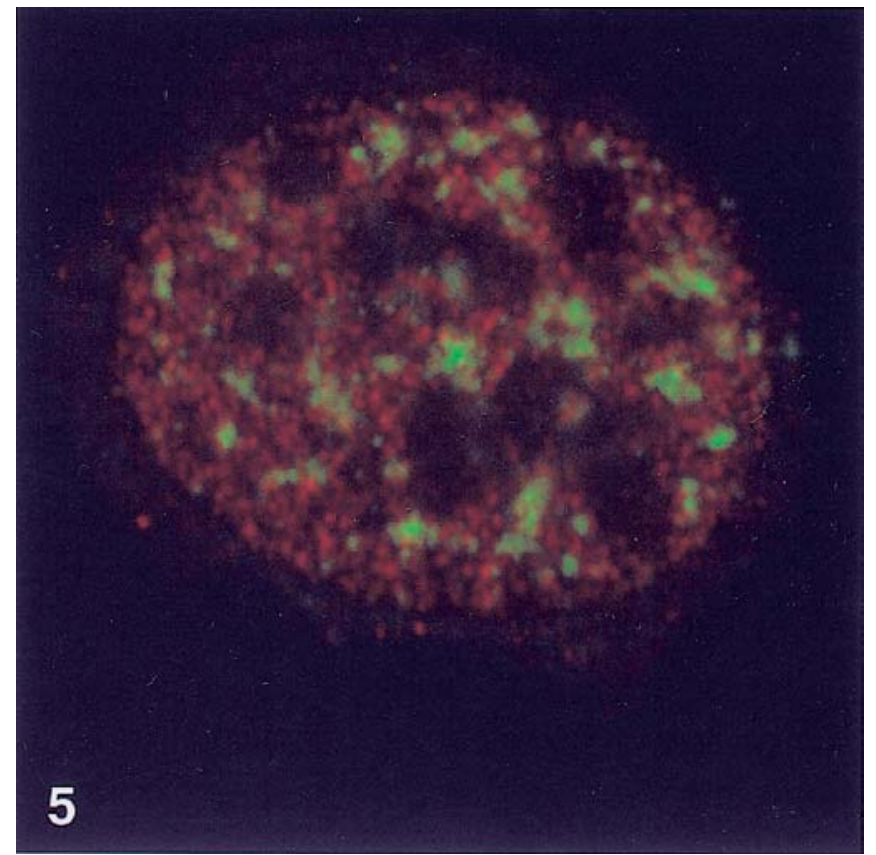

Fig. 5 Confocal optical section of a T24 cell labelled for $10 \mathrm{~min}$ following microinjection of Br-UTP. This figure shows a merge after a double labelling of newly synthesised RNA (red colour) and of a PANA protein marker of interchromatin granules clusters (green). It shows very little overlapping of the two labels. Fore more details, see Cmarko et al. (1999). Micrograph courtesy of Pernette Verschure (x 4,000)

tion with pre-mRNA transcription factors, such as RNA polymerase II or TFIIH (Cmarko et al. 1999).

\section{Pre-mRNA processing}

Perichromatin fibrils located within the perichromatin region have been demonstrated as accumulating all so far probed factors involved in or associated with pre-mRNA processing. These are namely snRNPs (Fakan et al. 1984; Puvion et al. 1984; Fig. 7), $m_{3} \mathrm{G}$ cap structure of snRNAs (Malatesta et al. 1994a; Trentani et al. 2003), SC-35 protein (Spector et al. 1991), poly(A) polymerase (Cmarko et al. 1999) and survival of motor neuron (SMN) protein (Malatesta et al. 2004). Similarly, ISH experiments using oligo-dT probes identified poly(A)-containing RNA in perichromatin fibrils (Visa et al. 1993a; Huang et al. 1994). The fact that perichromatin fibrils are the only nucleoplasmic structural constituent containing rapidly labelled RNA, as well as all transcription and processing factors, strongly support that they are also the site where most pre-mRNA processing steps take place. This is also in line with previously reported observations (see, for example, Fakan et al. 1986; Beyer and Osheim 1988; Wieslander et al. 1996) suggesting that pre-mRNA splicing occurs co-transcriptionally.

Immunoelectron microscopic assays also demonstrated the presence of hnRNP core proteins in perichromatin granules, structural constituents located almost exclu- 


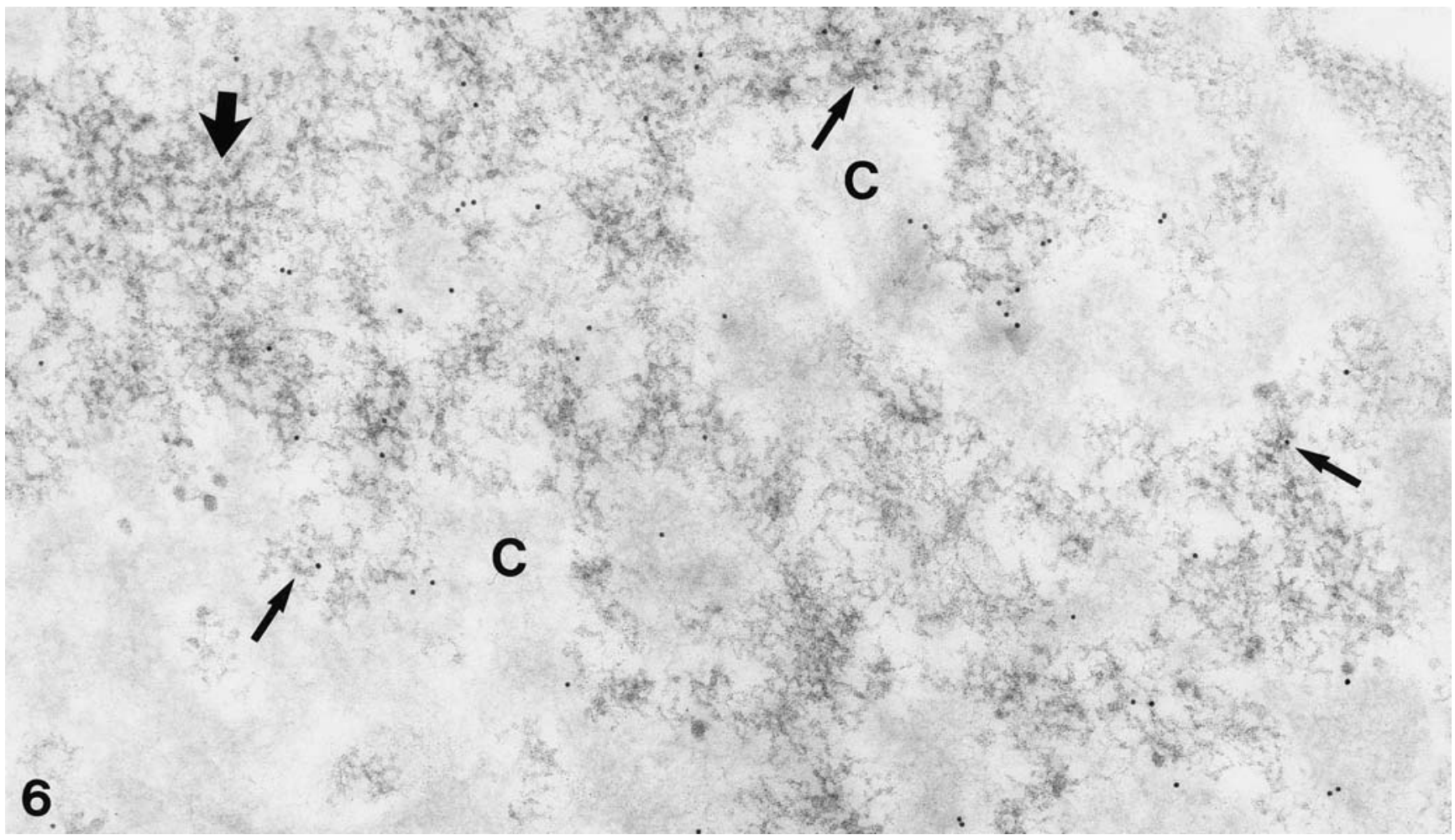

Fig. 6 Ultrathin section of an HTC cell nucleus labelled for $10 \mathrm{~min}$ after microinjection of Br-UTP. EDTA staining preferential for nuclear RNPs. Newly synthesised RNA is mostly associated with perichromatin fibrils (some indicated by small arrows) occurring on the periphery of condensed chromatin areas $(C)$. Interchromatin granule cluster (large arrow) remains unlabelled. For more details, see Cmarko et al. (1999). Micrograph by Dusan Cmarko. $(\times 63,000)$ sively in perichromatin regions (Fakan and Puvion 1980). Similar to Balbiani ring granules of Chironomus polytene nuclei by their morphology and cytochemical nature (Vazquez-Nin and Bernhard 1971), as well as by RNA arrangement within the granule (Vazquez-Nin et al. 1996, 1997a), perichromatin granules have been shown as being involved in intranuclear pre-mRNA storage and transport in hormone target cells (Vazquez-Nin et al. 1997b). This is in agreement with extensively documented evidence about Balbiani ring granules as intranuclear vectors of large already processed pre-mRNA molecules (for review see Daneholt 2001), while splicing factor association was reported only within the Balbiani ring during the granule formation from the transcript (Vazquez-Nin et al. 1990). Perichromatin granules occur individually and can occasionally be observed as winding from a perichromatin fibril (Fig. 1). It is, therefore, obvious that at least some transcripts give rise to perichromatin granules which are then vehicled in the nucleus.

\section{Interchromatin space}

Two major structural domains are observed in the interchromatin space of mammalian and most eukaryotic cells: interchromatin granule clusters (IGs) and the Cajal (coiled) bodies (CBs). Cytochemical analyses demon- strated the presence of RNA in both these constituents (Monneron and Bernhard 1969).

\section{Interchromatin granules}

This remarkable nucleoplasmic domain has been shown to accumulate pre-mRNA splicing factors such as snRNPs (Spector et al. 1983; Fakan et al. 1984; Puvion et al. 1984; Fig. 7), the splicing factor SC-35 (Spector et al. 1991) and the $\mathrm{m}_{3} \mathrm{G}$ cap of snRNAs (Malatesta et al. 1994a; Trentani et al. 2003). Autoradiographic evidence of ${ }^{3} \mathrm{H}$-uridine incorporation into cultured cells or later of $\mathrm{Br}-\mathrm{UTP}$ or $\mathrm{Br}$ uridine labelling showed that IGs are virtually devoid of newly synthesised RNA (Fakan and Bernhard 1971; Fakan et al. 1976; Cmarko et al. 1999; Trentani et al. 2003) as well as of hnRNP core proteins (Fakan et al. 1984). These observations were corroborated by immunofluorescence assays (for review see Spector 2003), using different anti-splicing factor antibodies, usually giving rise to a diffuse labelling together with a number of "speckles" (see Spector 2003; Lamond and Spector 2003 for review), some of them corresponding to IGs, while the diffuse signal and some of the small speckles obviously represent labelling of PFs. The application of anti-hnRNP antibodies leads only to a diffuse labelling pattern (Martin and Okamura 1981). In situ hybridisation assays using oligo-dT probes at both light and electron microscopic 


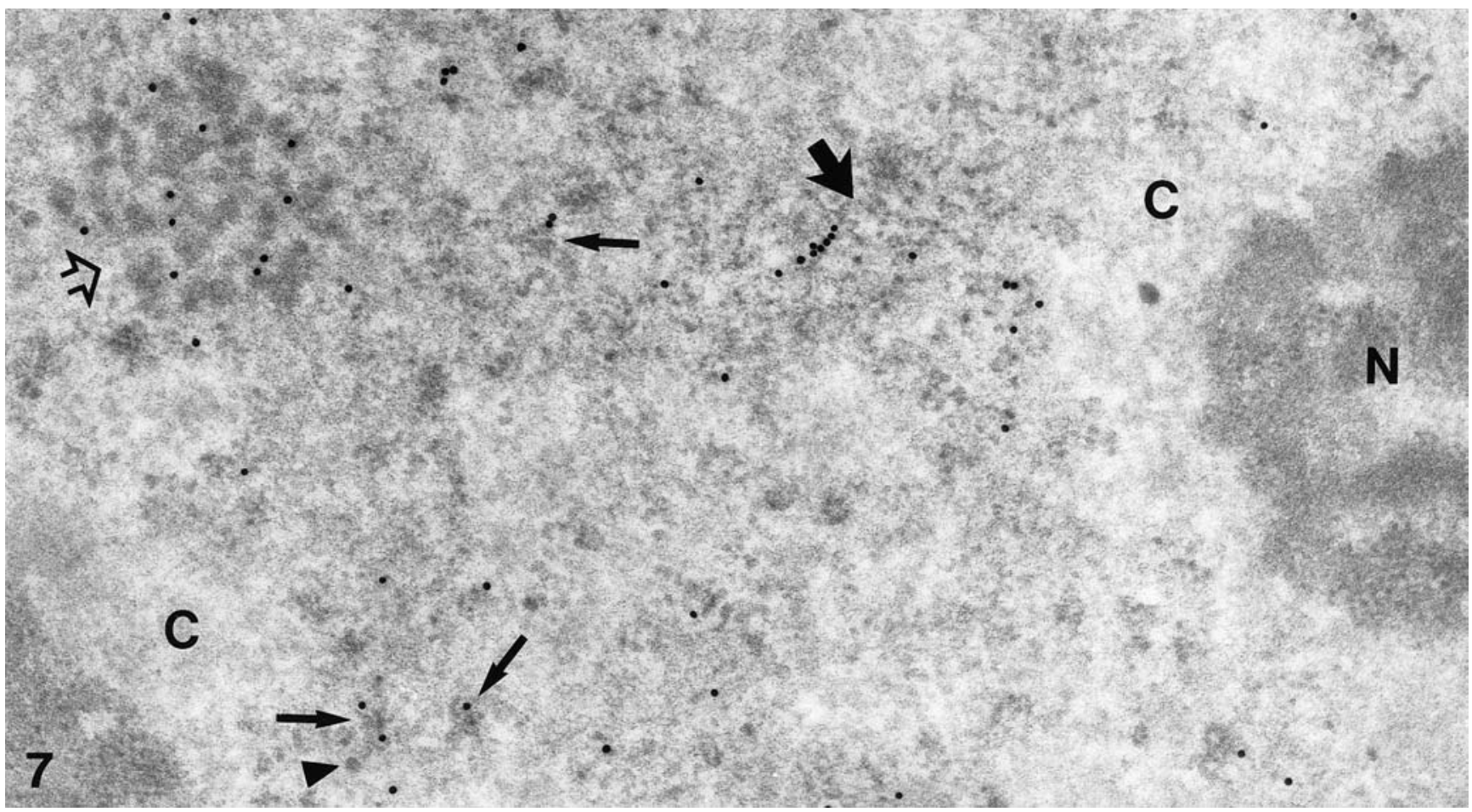

Fig. 7 Ultrathin section of a rat hepatocyte labelled with an autoimmune antibody recognising the Sm antigen of snRNPs. The signal is mainly associated with perichromatin fibrils (small ar- rows), a cluster of interchromatin granules (large arrow) and a Cajal (coiled) body (open arrow). Arrowhead Perichromatin granule, $C$ condensed chromatin, $N$ nucleolus. $(\times 53,750)$ levels show more or less significant labelling associated with IGs (speckles) (see, for example, Visa et al. 1993a; Huang et al. 1994) suggesting the occurrence of poly(A)containing RNA within IGs. A detailed immunofluorescence microscopic quantitative digital analysis of nascent Br-RNA, SC-35 factor and poly(A) distribution in nuclei of cultured cells reported that, for all probes examined, most of the signal was diffusely spread throughout the nucleoplasm. SC-35 label was especially diffusely distributed in the nucleoplasm (70-80\%), whereas only a minor portion was concentrated in IGs (speckles) (Fay et al. 1997). This also clearly argues that splicing factors are not markers of speckles as erroneously reported in a number of fluorescence microscopic investigations. However, speckles can be specifically revealed by virtue of marker proteins, such as PANA (Clevenger and Epstein 1984; Fig. 5). Together, these different findings show that IG clusters are not sites of hnRNA transcription. This is also supported by the absence of significant signal for RNA polymerase II in this nucleoplasmic domain (Cmarko et al. 1999), some previous immunofluorescence observations of RNA polymerase II in speckles being recently explained as preparative artefacts (Guillot et al. 2004). The absence of poly(A) polymerase also rules out IGs as sites of polyadenylation (Cmarko et al. 1999). Taking into account the above observations, the question arises as to the role IGs can play in pre-mRNA metabolism. Original immunoelectron microscopic data suggested that this nucleoplasmic domain could be a storage site for pre-mRNA splicing factors (Fakan et al. 1984) and strong evidence for this hypothesis came from an elegant in vivo demonstration by time-lapse microscopy of a splicing factor delivery from speckles towards sites of pre-mRNA transcription (Misteli et al. 1997). Further information about a possible involvement of IGs in transcription and pre-mRNA splicing was provided by experiments making use of the serine-arginine (SR) protein kinase cdc2-like kinase Clk/STY to manipulate the integrity of IG clusters in vivo. Immunofluorescence, as well as transmission electron microscopic analyses, revealed that overexpression of Clk/STY gives rise to dispersion of IGs within the nucleoplasm, whereas this phenomenon was not observed with an inactive mutant. Thus, it seems that hyperphosphorylation of SR proteins provokes IG dispersion. Moreover, these observations also indicated that cells lacking IG clusters continued to synthesise pre-mRNA, while accumulation of splicing factors at sites of pre-mRNA synthesis and splicing itself were strongly reduced, pointing out that the integrity of IG clusters was important for coordination of transcription and splicing (Sacco-Bubulya and Spector 2002). While the role of IGs in splicing factor storage and/or assembly of pre-spliceosome seems now well established, the nature of polyadenylated RNA occurring in IG clusters and its possible role in this nucleoplasmic domain remain enigmatic. Ultrastructural ISH assays suggested that some viral RNAs occur in IGs of HSV-1 infected cells (Puvion and Puvion-Dutilleul 1996), whereas HIV-1 intron-containing pre-mRNA sequences accumulated only on the periphery of IG clusters in nuclei of cells 
transfected with a rev-minus construct (Cmarko et al. 2002). Fluorescence microscopic observations reported from in vivo ISH trials provided contradictory results indicating either diffused distribution of poly(A) RNA without special accumulation when using oligo(dT) (Politz et al. 1999) or rather strong accumulation of poly(A) RNA in speckles after microinjection of $2^{\prime} 0$-methyl oligoribonucleotide probes complementary to poly(A) tail (Molenaar et al. 2004). Taking into account that premRNA forms complexes with hnRNP core proteins which accompany the RNA on its nuclear pathway (Dreyfuss et al. 2002) and the fact that IGs appear to be mostly devoid of hnRNP core proteins probed so far (see above) makes it difficult to accept that pre-mRNA accumulates in IG clusters. If so, the poly(A) RNA fraction present there should be able to dissociate from its core proteins before entering the IG clusters and reassociate with them again in case of transient interaction with speckles. However, it is also possible that IG clusters represent a domain involved in RNA decay mechanism, where previously modified hnRNA-protein complexes or other types of nuclear RNA migrate. Keeping in mind that most nuclear RNA represents non-protein-coding RNAs, many of them being polyadenylated (Mattick 2003), this possibility must be taken into consideration.

A domain named IG-associated zones (IGAZ) can be observed close to IG clusters (Visa et al. 1993b). Exhibiting a finely fibrillar rather homogeneous texture, it has been shown to contain U1 but not U2 snRNA, Sm antigen of snRNPs (Visa et al. 1993b), some transcription factors, as well as moderate amounts of newly synthesised RNA after longer labelling periods (Cmarko et al. 1999) and SMN protein (Malatesta et al. 2004). Originally proposed as possible maturation sites of the U1 snRNP particle (Visa et al. 1993b), its involvement in pre-mRNA processing pathways still remains obscure.

\section{Cajal (coiled) body}

The CB is a mostly nucleoplasmic domain, of which fine structural features and cytochemical nature were examined in detail by ultrastructural methods (Monneron and Bernhard 1969). Containing both nucleoplasmic (snRNP and snRNA but not SR-rich splicing factors) (Fig. 7) and nucleolar (fibrillarin, U3 snRNA) processing components, it behaves as a dynamic structure (for review see Gall 2003). Observed either free in the nucleoplasm or associated with nucleoli (see, for example, Malatesta et al. 1994b), the CB is abundant in nuclei of various tissues of hibernating dormice (Malatesta et al. 1994a). The occurrence of the marker protein p80-coilin in CBs (Raska et al. 1991) made it possible to follow reticulated structures giving rise to $\mathrm{CBs}$ at the onset of hibernation, and the dispersion and disappearance of its constituents in the nucleoplasm and nucleoli during the animal arousal. In vivo fluorescence microscopic analysis of a cell line stably expressing a fusion protein of p80-coilin with GFP suggested movement of CBs throughout the nucleoplasm and between the nucleoplasm and the nucleoli (Platani et al. 2000).

Recent ultrastructural investigation analysed the structural and topological relationships between $\mathrm{CBs}$ and a newly described nuclear domain accumulating SMN and Gemin2 proteins and named electron-dense fibrogranular clusters (EFGCs; Malatesta et al. 2004). This obviously corresponds to the domain previously reported by fluorescence microscopy as gemini of CBs (gems; Liu and Dreyfuss 1996). EFGCs and CBs were occasionally found closely associated but usually distant from each other (Malatesta et al. 2004). These two domains seem to be involved in splicing factor storage and assembly and a recent detailed fluorescence microscopic analysis suggested that they are kinetically independent structures (Dundr et al. 2004). The elucidation of their role in nuclear functions will require further investigations.

\section{Concluding remarks and perspectives}

The different data discussed above point out essential contributions made by ultrastructural cytochemistry in analysing the functional nuclear architecture. In spite of the two-dimensional nature of EM images, various cytochemical methods adapted to transmission electron microscopic application represent a major high resolution tool for investigating structure-function relationships in the cell. Presently offering a rather large scale of preparative techniques mostly consisting in different chemical fixation approaches combined with resin embedding or cryoultramicrotomy, they also involve cryofixation and cryosubstitution procedures excluding conventional fixatives (von Schack and Fakan 1993). Contrary to modern EM cytochemical methods mainly applied on specimens embedded into different resins stabilising the cellular fine structural features, many light microscopic techniques require harsh treatments of cells, such as permeabilisation and denaturation, which can give rise to extraction or displacement of nuclear proteins or nucleic acids. This must be kept in mind, in addition to the limits of resolution, when interpreting light microscopic data. Recent developments of live cell microscopy opened a new way of investigation of cellular processes including real-time studies of inducible gene expression systems (see, for example, Janicki et al. 2004; Roix and Misteli 2002). Such observations combined with subsequent ultrastructural cytochemical analysis of the same cells offers an ideal complementary approach to the understanding of functional nuclear architecture and represents a major direction for the future.

Most of the above-mentioned ultrastructural investigations of the topology of nuclear functions, such as DNA replication, transcription and pre-mRNA processing, point out the central role played by the perichromatin region as a functional domain in the nucleus. The localisation of transcription sites reflects the location of most active genes in the perichromatin region. Evidence about the diffusion of relatively large molecules or molecular 
complexes within compact nuclear compartments (Verschure et al. 2003) suggests that the organisation of the perichromatin region situated on the border of rather compact condensed chromatin areas is likely to be independent of accessibility problems. Further questions can arise as to whether silenced or momentarily inactive genes also occur within the perichromatin region. Data provided by an ultrastructural study on the intranuclear distribution of polycomb group gene silencing proteins indicate that these proteins concentrate on the border of condensed chromatin (Cmarko et al. 2003), thus suggesting that some epigenetically silenced genes are also located in this nucleoplasmic domain. Another question related to possible functions of the perichromatin region regards pre-mRNA movement in the nucleus. Assuming that a portion of pre-mRNA is packed into perichromatin granules and knowing that the granules mostly occur within perichromatin regions, one can expect that these granules are vehicled along perichromatin regions towards the nuclear pores. Whether such a movement corresponds to a kind of channelled diffusion as previously suggested (Kramer et al. 1994) remains an open question. Free diffusion has been favoured as a model for RNA movement throughout the nucleoplasm (see, for example, Singh et al. 1999; Politz and Pederson 2000), while others proposed an energy-dependent mechanism (Molenaar et al. 2004). The pathways of different types of RNA with regards to nuclear compartments remains a major issue to be studied in the future. In this context, it may be interesting to mention the association of proteins involved in cellular mobility, such as actin and myosin with transcriptionally active genes (Fomproix and Percipalle 2004; Pestic-Dragovich et al. 2000), as well as to question a possible function of intranuclear lamins (Hozak et al. 1995; Shumaker et al. 2003).

Structural domains occurring in the interchromatin space such as IG clusters or CBs are obviously involved in storage of pre-mRNA processing factors and their delivery to sites of pre-mRNA transcription and processing. We do not know yet the structural turnover of these domains. In addition, more information is needed about the formation of $\mathrm{CBs}$ and the relationship between those observed in the nucleolus and in the nucleoplasm.

We also lack major information about the internal organisation of the nucleus and the way in which different nuclear domains are generated. Self organisation of nuclear structure would promote both architectural stability and dynamic behaviour of its components (Misteli 2001). The contribution of macromolecular crowding effects has recently been suggested as playing a role in driving the formation and maintaining the functions of nuclear compartments (Hancock 2004). The nuclear matrix, an operational term for residual intranuclear fibrogranular, predominantly protein network was proposed as a scaffolding system in the nuclear architecture. However, no clear evidence about the existence of such a structural network in the intact cell nucleus in situ has been provided so far (for detailed discussion, see Hancock 2000; Pederson 2000).
Finally, we still lack information about relationships between nuclear architecture and regulation of gene expression, including modifications at the level of DNA or histones. Regulatory mechanisms integrated at different levels (sequence to chromatin to three-dimensional spatial organisation of the genome in the nucleus) are poorly understood in the topological context of nuclear architecture (for detailed discussion, see van Driel et al. 2003) and will certainly represent a major topic of investigation in the future.

In conclusion, ultrastructural cytochemistry continues to contribute extensively to unravelling important questions regarding functional nuclear architecture. It is essential to combine different high standard microscopic approaches in order to take up such a complex challenge.

Acknowledgements The author would like to thank Drs. M. Biggiogera, M. Malatesta and T. Martin for critical reading of the manuscript and constructive comments, Mrs. L. Hautle for the preparation of the manuscript and Mr. W. Blanchard for photographic work. Research in the author's laboratory has been supported by the Swiss National Science Foundation.

\section{References}

Bernhard W (1969) A new staining procedure for electron microscopical cytology. J Ultrastruct Res 27:250-265

Beyer AL, Osheim YN (1988) Splice site selection rate of splicing and alternative splicing on nascent transcripts. Genes Dev 2:754-765

Biggiogera M, Fakan S (1998) Fine structural specific visualization of RNA on ultrathin sections. J Histochem Cytochem 46:389395

Biggiogera M, Courtens JL, Derenzini M, Fakan S, HernandezVerdun D, Risueno MC, Soyer-Gobillard MO (1996) Osmium ammine: review of current applications to visualize DNA in electron microscopy. Biol Cell 87:121-132

Biggiogera M, Malatesta M, Abolhassani-Dadras S, Amalric F, Rothblum LI, Fakan S (2001) Revealing the unseen: the organizer region of the nucleolus. J Cell Sci 114:3199-3205

Clevenger C, Epstein A (1984) Component of interchromatin granules using a monoclonal antibody and immunogold electron microscopy. Exp Cell Res 151:194-207

Cmarko D, Verschure PJ, Martin TE, Dahmus ME, Krause S, Fu XD, van Driel R, Fakan S (1999) Ultrastructural analysis of transcription and splicing in the cell nucleus after bromo-UTP microinjection. Mol Biol Cell 10:211-223

Cmarko D, Verschure PJ, Rothblum LI, Hernandez-Verdun D, Amalric F, vanDriel R, Fakan S (2000) Ultrastructural analysis of nucleolar transcription in cells microinjected with 5-bromoUTP. Histochem Cell Biol 113:131-187

Cmarko D, Boe SO, Scassellati C, Szilvay AM, Davanger S, Fu XD, Haukenes G, Kalland KH, Fakan S (2002) Rev inhibition strongly affects intracellular distribution of human immunodeficiency virus type 1 RNAs. J Virol 76:10473-10484

Cmarko D, Verschure PJ, Otte AP, van Driel R, Fakan S (2003) Polycomb group gene silencing proteins are concentrated in the perichromatin compartment of the mammalian nucleus. J Cell Sci 116:335-343

Cogliati R, Gautier A (1973) Mise en évidence de l'ADN et des polysaccharides à l'aide d'un nouveau réactif "de type Schiff". C R Acad Sci Paris Ser D 276:3041-3044

Cremer T, Cremer C (2001) Chromosome territories, nuclear architecture and gene regulation in mammalian cells. Nat Rev Gen 2:292-301

Daneholt B (2001) Assembly and transport of a premessenger RNP particle. Proc Natl Acad Sci U S A 98:7012-7017 
Dreyfuss G, Kim VN, Kataoka N (2002) Messenger-RNA-binding proteins and the messages they carry. Mol Cell Biol 3:195-205

Dundr M, Hebert MD, Karpova TS, Stanek D, Xu H, Shpargel KB, Meier UT, Neugebauer KM, Matera AG, Misteli T (2004) In vivo kinetics of Cajal body components. J Cell Biol 164:831842

Esquivel C, Vázquez-Nin GH, Echeverría O (1989) Evidence of repetitive patterns of chromatin distribution in cell nuclei of rat liver. Acta Anat 136:94-98

Fakan S (1978) High resolution autoradiography studies on chromatin functions. In: Busch $\mathrm{H}$ (ed) The cell nucleus, vol 5. Academic, New York, pp 3-54

Fakan S (1994) Perichromatin fibrils are in situ forms of nascent transcripts. Trends Cell Biol 4:86-90

Fakan S, Bernhard W (1971) Localization of rapidly and slowly labeled nuclear RNA as visualized by high resolution autoradiography. Exp Cell Res 67:129-141

Fakan S, Hancock R (1974) Localization of newly-synthesized DNA in a mammalian cell as visualized by high resolution autoradiography. Exp Cell Res 83:95-102

Fakan S, Puvion E (1980) The ultrastructural visualization of nucleolar and extranucleolar RNA synthesis and distribution. Int Rev Cytol 65:255-299

Fakan S, Puvion E, Spohr G (1976) Localization and characterization of newly synthesized nuclear RNA in isolated rat hepatocytes. Exp Cell Res 99:155-164

Fakan S, Leser G, Martin TE (1984) Ultrastructural distribution of nuclear ribonucleoproteins as visualized by immunocytochemistry on thin sections. J Cell Biol 98:358-363

Fakan S, Leser G, Martin TE (1986) Immunoelectron microscope visualization of nuclear ribonucleoprotein antigens within spread transcription complexes. J Cell Biol 103:1153-1157

Fay FS, Taneja KL, Shenoy S, Lifshitz L, Singer RH (1997) Quantitative digital analysis of diffuse and concentrated nuclear distribution of nascent transcripts, SC35 and poly(A). Exp Cell Res 231:27-37

Fomproix N, Percipalle P (2004) An actin-myosin complex on actively transcribing genes. Exp Cell Res 294:140-148

Gall JG (2003) The centennial of the Cajal body. Nat Rev Mol Cell Biol 4:975-980

Goessens G (1984) Nucleolar structure. Int Rev Cytol 87:107-157

Granboulan N, Granboulan P (1965) Cytochimie ultrastructurale du nucléole. II. Etude des sites de synthèse du RNA dans le nucléole et le noyau. Exp Cell Res 38:604-619

Guillot PV, Xie SQ, Hollinshead M, Pombo A (2004) Fixationinduced redistribution of hyperphosphorylated RNA polymerase II in the nucleus of human cells. Exp Cell Res 295:460-468

Hancock R (2000) A new look at the nuclear matrix. Chromosoma 109:219-225

Hancock R (2004) A role for macromolecular crowding effects in the assembly and function of compartments in the nucleus. J Struct Biol 146:281-290

Hozak P (1995) Catching RNA polymerase I in flagranti: ribosomal genes are transcribed in the dense fibrillar component of the nucleolus. Exp Cell Res 216:285-289

Hozak P, Sasseville AM, Raymond Y, Cook PR (1995) Lamin proteins form an internal nucleoskeleton as well as a peripheral lamina in human cells. J Cell Sci 108:635-344

Huang S, Deerinck TJ, Ellisman MH, Spector DL (1994) In vivo analysis of the stability and transport of nuclear poly(A)+ RNA. J Cell Biol 126:877-899

Huberman JA, Riggs AD (1968) On the mechanism of DNA replication in mammalian chromosomes. J Mol Biol 32:327-341

Jackson DA, Hassan AB, Errington RJ, Cook PR (1993) Visualization of focal sites of transcription within human nuclei. EMBO J 12:1059-1065

Janicki SM, Tsukamoto T, Salghetti SE, Tansey WP, Sachidanandam R, Prasanth KV, Ried T, Shav-Tal Y, Bertrand E, Singer RH, Spector DL (2004) From silencing to gene expression: real-time analysis in single cells. Cell 116:683-698

Jaunin F, Fakan S (2002) DNA replication and nuclear architecture. J Cell Biochem 85:1-9
Jaunin F, Visser AE, Cmarko D, Aten JA, Fakan S (1998) A new immunocytochemical technique for ultrastructural analysis of DNA replication in proliferating cells after application of two halogenated deoxyuridines. J Histochem Cytochem 46:12031209

Jaunin F, Visser AE, Cmarko D, Aten JA, Fakan S (2000) Fine structural in situ analysis of nascent DNA movement following DNA replication. Exp Cell Res 260:313-323

Jones RE, Okamura C, Martin TE (1980) Immunofluorescent localization of the proteins of nuclear ribonucleoprotein complexes. J Cell Biol 86:235-243

Kramer J, Zachar Z, Bingham PM (1994) Nuclear pre-mRNA metabolism: channels and tracks. Trends Cell Biol 4:35-37

Lamond AI, Spector DL (2003) Nuclear speckles: a model for nuclear organelles. Mol Cell Biol 4:605-612

Leblond CP, el-Alfy M (1996) The eleven stages of the cell cycle, with emphasis on the changes in chromosomes and nucleoli during interphase and mitosis. Anat Rec 252:426-443

Leser GP, Escara-Wilke J, Martin TE (1984) Monoclonal antibodies to heterogenous nuclear RNA-protein complexes. The core proteins comprise a conserved group of related polypeptides. J Biol Chem 259:1827-1833

Liu Q, Dreyfuss G (1996) A novel nuclear structure containing the survival of motor neurons protein. EMBO J 15:3555-3565

Liu DF, el-Alfy M, Leblond CP (1995) DNA changes involved in the formation of metaphase chromosomes, as observed in mouse duodenal crypt cells stained by osmium-amine. II. Tracing nascent DNA by bromodeoxyuridine into structures arising during the S-phase. Anat Rec 242:449-461

López-Velázquez G, Márquez J, Ubaldo E, Corkidi G, Echeverría O, Vázquez Nin GH (1996) Three-dimensional analysis of the arrangement of compact chromatin in the nucleus of G0 rat lymphocytes. Histochem Cell Biol 105:153-161

Malatesta M, Zancanaro C, Martin TE, Chan EKL, Amalric F, Lührmann R, Vogel P, Fakan S (1994a) Cytochemical and immunocytochemical characterization of nuclear bodies during hibernation. Eur J Cell Biol 65:82-93

Malatesta M, Zancanaro C, Martin TE, Chan EKL, Amalric F, Lührmann R, Vogel P, Fakan S (1994b) Is the coiled body involved in nucleolar functions? Exp Cell Res 211:415-419

Malatesta M, Scassellati C, Meister G, Plöttner O, Bühler D, Sowa G, Martin TE, Keidel E, Fischer U, Fakan S (2004) Ultrastructural characterisation of a nuclear domain highly enriched in survival of motor neuron (SMN) protein. Exp Cell Res 292:312-321

Martin TE, Okamura CS (1981) Immunocytochemistry of nuclear hnRNP complexes. In: Busch H (ed) The cell nucleus, vol 9. Academic, New York, pp 119-144

Mattick JS (2003) Challenging the dogma: the hidden layer of non-protein-coding RNAs in complex organisms. Bioessays 25:930-939

Misteli T (2001) The concept of self-organization in cellular architecture. J Cell Biol 155:181-185

Misteli T, Caceres JF, Spector DL (1997) The dynamics of a premRNA splicing factor in living cells. Nature 387:523-527

Molenaar C, Abdulle A, Gena A, Tanke HJ, Dirks RW (2004) Poly(A)+ RNAs roam the cell nucleus and pass through speckle domains in transcriptionally active and inactive cells. J Cell Biol 165:191-202

Monneron A, Bernhard W (1969) Fine structural organization of the interphase nucleus in some mammalian cells. J Ultrastruct Res 27:266-288

Nash RE, Puvion E, Bernhard W (1975) Perichromatin fibrils as components of rapidly labeled extranucleolar RNA. J Ultrastruct Res 53:395-405

O'Keefe RT, Henderson SC, Spector DL (1992) Dynamic organization of DNA replication in mammalian cell nuclei: spatially and temporally defined replication of chromosome-specific $\alpha$ satellite DNA sequences. J Cell Biol 116:1095-1110

Pederson T (2000) Half a century of "the nuclear matrix". Mol Biol Cell 11:799-805 
Pestic-Dragovich L, Stojiljkovic L, Philimonenko AA, Nowak G, Ke Y, Settlage RE, Shabanowitz J, Hunt DF, Hozak P, de Lanerolle P (2000) A myosin I isoform in the nucleus. Science 290:337-341

Platani M, Goldberg I, Swedlow JR, Lamond AI (2000) In vivo analysis of Cajal body movement, separation, and joining in live human cells. J Cell Biol 151:1561-1574

Politz JC, Pederson T (2000) Review: movement of mRNA from transcription site to nuclear pores. J Struct Biol 129:252-257

Politz JC, Turft RA, Pederson T, Singer RH (1999) Movement of nuclear poly(A) RNA throughout the interchromatin space in living cells. Cur Biol 9:285-291

Puvion E, Moyne G (1978) Intranuclear migration of newly synthesized extranucleolar ribonucleoproteins. A high resolution quantitative autoradiographical and cytochemical study. Exp Cell Res 115:79-88

Puvion E, Puvion-Dutilleul F (1996) Ultrastructure of the nucleus in relation to transcription and splicing: roles of perichromatin fibrils and interchromatin granules. Exp Cell Res 229:217-225

Puvion E, Viron A, Assens C, Leduc EH, Jeanteur P (1984) Immunocytochemical identification of nuclear structures containing snRNPs in isolated rat liver cells. J Ultrastruct Res $87: 180-189$

Raska I (2003) Oldies but goldies: searching for Christmas trees within the nucleolar architecture. Trends Cell Biol 13:517-525

Raska I, Andrade LE, Ochs RL, Chan EK, Chang CM, Roos G, Tan EM (1991) Immunological and ultrastructural studies of the nuclear coiled body with autoimmune antibodies. Exp Cell Res 195:27-37

Roix J, Misteli T (2002) Genomes, proteomes, and dynamic networks in the cell nucleus. Histochem Cell Biol 118:105-116

Sacco-Bubulya P, Spector DL (2002) Disassembly of interchromatin granule clusters alters the coordination of transcription and pre-mRNA splicing. J Cell Biol 156:425-436

Shumaker DK, Kuczmarski ER, Goldman RD (2003) The nucleoskeleton: lamins and actin are major players in essential nuclear functions. Curr Opin Cell Biol 15:358-366

Singh OP, Björkroth B, Masich S, Wieslander L, Daneholt B (1999) The intranuclear movement of Balbiani ring premessenger ribonucleoprotein particles. Exp Cell Res 251:135-146

Smetana K, Steele WJ, Busch H (1963) A nuclear ribonucleoprotein network. Exp Cell Res 182:521-533

Sobczak-Thepot J, Harper F, Florentin Y, Zindy F, Brechot C, Puvion E (1993) Localization of cyclin A at the sites of cellular DNA replication. Exp Cell Res 206:43-48

Solovei I, Cavallo A, Schermelleh L, Jaunin F, Scassellati C, Cmarko D, Cremer C, Fakan S, Cremer T (2002) Spatial preservation of nuclear chromatin architecture during threedimensional fluorescence in situ hybridization (3D-FISH). Exp Cell Res 276:10-23

Spector DL (2003) The dynamics of chromosome organization and gene regulation. Annu Rev Biochem 72:573-608

Spector DL, Schrier WH, Busch H (1983) Immunoelectron microscopic localization of snRNPs. Biol Cell 49:1-10

Spector DL, Fu XD, Maniatis T (1991) Associations between distinct pre-mRNA splicing components and the cell nucleus. EMBO J 10:3467-3481

Stelzer EHK (1995) The intermediate optical system of laserscanning confocal microscopes. In: Pawley JB (ed) Handbook of biological confocal microscopy. Plenum, New York, pp 139154
Swift H (1962) Nucleoprotein localization in electron micrographs: metal binding and radioautography. In: Harris RJC (ed) The interpretation of ultra-structure. Symposia of the International Society for Cell Biology, vol 1. Academic, New York, pp 213232

Trentani A, Testillano PS, Risueño MC, Biggiogera M (2003) Visualization of transcription sites at the electron microscope. Eur J Histochem 47:195-200

van der Ploeg J (2000) Cytochemical nucleic acid research during the twentieth century. Eur J Hictochem 44:7-42

van Driel R, Fransz PF, Verschure PJ (2003) The eukaryotic genome: a system regulated at different hierarchical levels. J Cell Sci 116:4067-4075

Vazquez-Nin GH, Bernhard W (1971) Comparative ultrastructural study of perichromatin- and Balbiani ring granules. J Ultrastruct Res 36:842-860

Vazquez-Nin GH, Echeverria OM, Fakan S, Leser G, Martin TE (1990) Immunoelectron microscope localization of snRNPs in the polytene nucleus of salivary glands of Chironomus thummi. Chromosoma 99:44-51

Vazquez-Nin GH, Abolhassani-Dadras S, Echeverria OM, Boutinard Rouelle-Rossier V, Fakan S (1996) Phosphorus distribution in perichromatin granules and surrounding nucleoplasm as visualized by electron spectroscopic imaging. Biol Cell $87: 171-177$

Vazquez-Nin GH, Abolhassani-Dadras S, Echeverria OM, Boutinard Rouelle-Rossier V, von Schack ML, Fakan S (1997a) Electron spectroscopic imaging analyses of the distribution of phosphorus in Balbiani ring granules and in the surrounding nucleoplasm. Chromosoma 105:360-368

Vazquez-Nin GH, Echeverria OM, Ortiz R, Ubaldo E, Fakan S (1997b) Effects of hypophyseal hormones on transcription and RNA export to the cytoplasm. Exp Cell Res 236:519-526

Verschure PJ, van der Kraan I, Manders EMM, Hoogstraten D, Houtsmuller AB, van Driel R (2003) Condensed chromatin domains in the mammalian nucleus are accessible to large macromolecules. EMBO Rep 4:861-866

Visa N, Puvion-Dutilleul F, Harper F, Bachellerie JP, Puvion E (1993a) Intranuclear distribution of poly(A) RNA determined by electron microscope in situ hybridization. Exp Cell Res 208:19-34

Visa N, Puvion-Dutilleul F, Bachellerie JP, Puvion E (1993b) Intranuclear distribution of U1 and U2 snRNAs visualized by high resolution in situ hybridization: revelation of a novel compartment containing U1 but not U2 snRNA in HeLa cells. Eur J Cell Biol 60:308-321

Visser AE, Jaunin F, Fakan S, Aten JA (2000) High resolution analysis of interphase chromosome domains. J Cell Sci 113:2585-2593

von Schack ML, Fakan S (1993) The study of the cell nucleus using cryofixation and cryosubstitution. Micron 24:507-519

Wansink DG, Schul W, van der Kraan I, van Steensel B, van Driel R, de Jong L (1993) Fluorescent labeling of nascent RNA reveals transcription by RNA polymerase II in domains scattered throughout the nucleus. J Cell Biol 122:282-293

Wieslander L, Baurén G, Bernholm K, Jiang WQ, Wetterberg I (1996) Processing of pre-mRNA in polytene nuclei of Chironomus tentans salivary gland cells. Exp Cell Res 229:240-246 